\title{
Pressure Alarm Device
}

National Cancer Institute

\section{Source}

National Cancer Institute. Pressure Alarm Device. NCI Thesaurus. Code C49816.

A device designed to signal the occurrence of a pressure fluctuation beyond an established range. 